\title{
Crohn's colitis and sarcoidosis
}

\author{
P.A. McCormick, D.P. O’Donoghue and M.X. FitzGerald \\ Departments of Gastroenterology and Respiratory Medicine, St. Vincent's Hospital, Elm Park, Dublin 4 and \\ Medical Professorial Unit, University College Dublin, Republic of Ireland.
}

\begin{abstract}
Summary: We report a patient with both sarcoidosis and Crohn's colitis, an association not previously documented. We review the literature and discuss the areas of overlap in these two conditions.
\end{abstract}

\section{Introduction}

Sarcoidosis and Crohn's disease are both granulomatous diseases of unknown aetiology, but rarely occur together in the same patient. We present a patient with well documented Crohn's colitis and sarcoidosis. Review of the literature suggests that overlap cases of Crohn's colitis and sarcoidosis can occur and may cause diagnostic difficulty.

\section{Case report}

In April 1982 a 29 year old doctor presented with a 4 week history of diarrhoea occurring 6 to 7 times a day and associated with the passage of blood and mucus. She had suffered from intermittent mild attacks of diarrhoea for a number of years, most marked during her 2 previous pregnancies. Physical examination was normal. Abnormal laboratory investigations included a white cell count of $11.8 \times 10^{9} / 1$ and an erythrocyte sedimentation rate (ESR) of $28 \mathrm{~mm} / \mathrm{h}$. Haemoglobin, serum albumin and urea and electrolytes were normal. A small bowel follow through was normal, but a barium enema showed areas of ulceration at the splenic and hepatic flexures. At colonoscopy the classical features of Crohn's colitis were seen - rectal sparing, aphthous ulceration, snail track ulcers and skip lesions. Biopsies of the ulcerated areas revealed non-specific inflammatory tissue with no granulomata. Biopsies of the macroscopically normal intervening tissue showed preservation of mucus secretion. She was treated with sulphasalazine $3 \mathrm{~g}$ orally per day and the diarrhoea resolved.

Five months later she had a recurrence of diarrhoea which responded to a short course of oral steroids. An

Correspondence: Professor M.X. FitzGerald, M.D., F.R.C.P., F.R.C.P.I., St. Vincent's Hospital, Elm Park, Dublin 4, Republic of Ireland.

Accepted: 8 May 1986 iron deficiency anaemia was noted and treated with oral iron. One year after her initial diagnosis of Crohn's disease she presented with a short history of anorexia, nausea and a $10 \mathrm{~kg}$ weight loss. She was on no medication at this time and her bowel habit was normal. Physical examination and routine laboratory investigations including haemoglobin, serum albumin and ESR were normal. Three weeks later she developed bilateral Bell's palsy and acute anterior uveitis. A chest X-ray showed bilateral hilar adenopathy and she was admitted to hospital for investigation of probable sarcoidosis. Lymph nodes obtained at mediastinoscopy showed masses of non-caseating granulomata. The serum angiotensin converting enzyme activity was raised at $41.8 \mathrm{U} / \mathrm{ml}$ (normal less than $30 \mathrm{U} / \mathrm{ml}$ ). Sputum cultures for M. tuberculosis were negative. Pulmonary function tests, including diffusing capacity for carbon monoxide, and serum and urinary calcium levels were normal. A diagnosis of sarcoidosis was thus confirmed and treatment with high dose oral steroids was started. She recovered rapidly and gained weight though she was left with some residual facial weakness. After 2 years of followup the bihilar lymphadenopathy has regressed but she has developed bilateral pulmonary infiltrates, with, however, excellent preservation of pulmonary function. She has had no further symptoms from her Crohn's disease.

\section{Discussion}

The concurrence of Crohn's disease and sarcoidosis is very rare. Only three definite cases (Oakley et al., 1983; Padilla \& Sparberg, 1972; Dines et al., 1971) and two possible cases (Dines et al., 1971; Morland, 1947) have been described in the literature. From the known prevalence of sarcoidosis (33 per 100,000: Logan, 1964) and the known incidence rate for Crohn's

(C) The Fellowship of Postgraduate Medicine, 1986 
disease (2.3 per 100,000; Humphreys et al., 1985) in Ireland we can estimate that one person in $10,000,000$ would present with both diseases in this country. Thus the association of Crohn's disease and sarcoidosis may possibly be ascribed to chance alone.

Despite the rarity of their occurrence together these two diseases share many clinical and immunological features which suggest that they may be more closely related. For example erythema nodosum, uveitis and arthritis occur in both and the Kveim test may be positive in Crohn's disease (Karlish et al., 1972). Two family studies have described the occurrence of Cro$\mathrm{hn}$ 's disease in some members and sarcoidosis in others (Willoughby et al., 1971; Gronhagen-Riska, 1983). In the latter study (Gronhagen-Riska, 1983) all affected but no unaffected members shared the HLA haplotype B8 and DR3, suggesting a genetic link. The similarities between these two diseases have prompted research into a possible common aetiology. In the 1960s animal transmission experiments demonstrated very similar results in both (Mitchell \& Rees, 1969, 1970). However despite these promising early results no definite transmissible agent has been identified in either condition. One of the arguments advanced against a link has been that there is pulmonary involvement in $90 \%$ of patients with sarcoidosis whereas the lung is spared in Crohn's disease. This view has been challenged by the very recent work of Smiejan et al. (1986) who have demonstrated the presence of 'sarcoid-like lymphocytosis' of the lower respiratory tract in patients with active Crohn's disease, but not in patients with other inflammatory bowel disorders. This is supported by another study which showed a transient impairment in pulmonary function in acute Crohn's disease (Heatley et al., 1982). These findings support the

\section{References}

AARONSON, H.G., MEIR, J.H. \& ULIN, A.W. (1957). A case of sarcoidosis of the colon. Journal of the Albert Einstein Medical Center, 6, 14.

CHINITZ, M.A., LAWRENCE, J.B., FRANK, M.S., FRAGER, D. \& SABLAY, L. (1985). Symptomatic sarcoidosis of the stomach. Digestive Diseases and Sciences, 30, 682.

DINES, D.E., DEREMEE, R.A. \& GREEN, P.A. (1971). Sarcoidosis associated with regional enteritis (Crohn's disease). Minnesota Medicine, 54, 617.

GOULD, S.R., HANDLEY, A.J. \& BARNARDO, D.E. (1973). Rectal and gastric involvement in a case of sarcoidosis. Gut, 14, 971.

GOUREVITCH, M.C. \& CUNNINGHAM, I.J. (1959). Sarcoidosis of the sigmoid colon. Postgraduate Medical Journal, 35, 689.

GRONHAGEN-RISKA, C., FYHRQUIST, F., HORTLING, L. \& KOSKIMIES, S. (1983). Familial occurrence of sarcoidosis and Crohn's disease. Lancet, $\mathbf{i}, 1287$.

HEATLEY, R.V., THOMAS, P., PROKIPCHUK, E.J., GAULDIE, J., SIENIEWICZ, D.J. \& BIENENSTOCK, J. (1982). Pulmon- theory that the pathogenetic mechanisms in sarcoidosis and Crohn's disease may have shared features.

Sarcoidosis of the intestinal tract has also been thought to be uncommon but there is some evidence that this may not be so. Chinitz et al. (1985) reviewed 20 patients with symptomatic gastric sarcoidosis and Palmer (1958) showed that as many as $10 \%$ of sarcoid patients had non-caseating granulomata in gastric mucosal biopsy specimens despite normal gastroscopic appearances. Isolated case reports of symptomatic and asymptomatic sarcoidosis of the intestine have appeared over the years (Sprague et al., 1984; Kohn, 1980; Gould et al., 1973; Gourevitch \& Cunningham, 1959; Aaronson et al., 1957; MacFarlane, 1955; Raven, 1949) although in many of these the diagnosis of systemic sarcoidosis was somewhat tenuous. Konda et al. (1980) described an interesting patient who presented with granulomatous hepatitis, a diffuse skin rash and was found to have a cobblestone appearance of the gastric mucosa and a diffusely friable rectal mucosa. Biopsies of the skin, rectum, stomach and an epitrochlear node all showed non-caseating granulomata. It must be a question of definition as to whether this patient had sarcoidosis with intestinal involvement, or Crohn's disease in addition to sarcoidosis.

In summary, Crohn's disease and sarcoidosis very rarely occur together. They share many clinical and immunological features and recent studies have $\operatorname{sug}_{\gtrless}$ gested that similar pathogenetic mechanisms may be involved in these two diseases. Further study of such overlap syndromes (James \& Sharma, 1985) may provide clues to the aetiology of these granulomatous disorders.

ary function abnormalities in patients with inflammatory bowel disease. Quarterly Journal of Medicine, 203, 241.

HUMPHREYS, W.G., BROWN, J.S. \& PARKS, T.G. (1985). The natural history of Crohn's disease in Northern Ireland. Irish Journal of Medical Science, 154, 372.

JAMES, D.G. \& SHARMA, O.P. (1985). Overlap syndromes with sarcoidosis. Postgraduate Medical Journal, 61, 769.

KARLISH, A.J., COX, E.V., HAMPSON, F. \& HEMSTED, E.H. (1972). The Kveim test in Crohn's disease, ulcerative colitis and coeliac disease. Lancet, i, 438.

KOHN, N.N. (1980). Sarcoidosis of the colon. Journal of the Medical Society of New Jersey, 77, 517.

KONDA, J., RUTH, M., SASSARIS, M. \& HUNTER, F.M. (1980). Sarcoidosis of the stomach and rectum. American Journal of Gastroenterology, 73, 516.

LOGAN, J. (1964). Prevalence of sarcoidosis in the Irish Republic. Acta Medica Scandinavica, 425 (Suppl), 126.

MACFARLANE, D.A. (1955). Intestinal sarcoidosis. British Journal of Surgery, 42, 639.

MITCHELL, D.N. \& REES, R.J.W. (1969). A transmissable 
agent from sarcoid tissue. Lancet, ii, 81 .

MITCHELL, D.N. \& REES, R.J.W. (1970). Agent transmissable from Crohn's disease tissue. Lancet, ii, 168.

MORLAND, A. (1947). A case of sarcoidosis of the lung with regional ileitis. Tubercle, $28,32$.

OAKLEY, J.R., LAWRENCE, D.A.S. \& FIDDIAN, R.V. (1983). Sarcoidosis associated with Crohn's disease of ileum, mouth and oesophagus. Journal of the Royal Society of Medicine, 76, 1068.

PALMER, E.D. (1958). Note on silent sarcoidosis of the gastric mocosa. Journal of Laboratory and Clinical Medicine, 52, 231.

PADILLA, A.J. \& SPARBERG, M. (1972). Regional enteritis and sarcoidosis in one patient. Gastroenterology, 63, 153.

SPRAGUE, R., HARPER, P., MCCLAIN, S., TRAINER, T. \&
BEEKEN, W. (1984). Disseminated gastrointestinal sarcoidosis: Case report and review of the literature. Gastroenterology, 87, 421.

RAVEN, R.W. (1949). The surgical manifestations of sarcoidosis. Annals of the Royal College of Surgeons of England, 5, 3.

SMIEJAN, J.M., COSNES, J., CHOLLET-MARTIN, S., SOLER, P., BASSET, F.M., LE QUINTREC, Y. \& HANCE, A.J. (1986). Sarcoid-like lymphocytosis of the lower respiratory tract in patients with active Crohn's disease. Annals of Internal Medicine, 104, 17.

WILLOUGHBY, J.M.T., MITCHELL, D.N. \& WILSON, J.D. (1971). Sarcoidosis and Crohn's disease in siblings. American Review of Respiratory Diseases, 104, 249. 